\title{
THE DEMAND FOR COCAINE AND MARIJUANA BY YOUTH
}

\author{
Frank J. Chaloupka \\ Michael Grossman \\ John A. Tauras
}

Working Paper 6411 


\title{
NBER WORKING PAPER SERIES
}

\section{THE DEMAND FOR COCAINE}

AND MARIJUANA BY YOUTH

\author{
Frank J. Chaloupka \\ Michael Grossman \\ John A. Tauras
}

\author{
Working Paper 6411 \\ http://www.nber.org/papers/w6411
}

\author{
NATIONAL BUREAU OF ECONOMIC RESEARCH \\ 1050 Massachusetts Avenue \\ Cambridge, MA 02138 \\ February 1998
}

This paper was prepared for the National Bureau of Economic Research conference on the Economic Analysis of Substance Use and Abuse, Cambridge, MA, March 27-28, 1997. Support for this research was provided by grant 5 RO1 DA07533 from the National Institute on Drug Abuse to the National Bureau of Economic Research. We are very grateful to Patrick O'Malley, Senior Research Scientist at the University of Michigan's Institute for Social Research, for enabling us to match drug prices and drug related policy variables to the Monitoring the Future data. We also thank Timothy J. Perry, Research Analyst at the Institute for Social Research, for his assistance in estimating the drug demand equations and Sara Markowitz for her research assistance. We owe a special debt to Carolyn G. Hoffman, Chief of the Statistical Analysis Unit of the U.S. Department of Justice's Drug Enforcement Administration, for providing us with data on cocaine prices from the System to Retrieve Information from Drug Evidence (STRIDE). Finally, we thank Henry Saffer and Charles C. Brown for helpful comments on this research. Any opinions expressed are those of the authors and not those of the National Bureau of Economic Research.

(C) 1998 by Frank J. Chaloupka, Michael Grossman and John A. Tauras. All rights reserved. Short sections of text, not to exceed two paragraphs, may be quoted without explicit permission provided that full credit, including (C) notice, is given to the source. 
The Demand for Cocaine and Marijuana by Youth

Frank J. Chaloupka, Michael Grossman

and John A. Tauras

NBER Working Paper No. 6411

February 1998

\begin{abstract}
In recent years, the debate over the costs and benefits of legalizing the use of currently illicit drugs has been revived. This paper attempts to inform this debate by providing some evidence on the effects of illicit drug prices and legal sanctions for drug possession and sale on youth drug use. Data on cocaine and marijuana use by high school seniors are taken from the 1982 and 1989 Monitoring the Future surveys. Site-specific data on cocaine prices and legal sanctions for the possession and sale, manufacture or distribution of cocaine and marijuana are added to the survey data. The results indicate that youth cocaine demand is sensitive to price, with average past year and past month cocaine demand elasticities of -1.28 and -1.43 , respectively. In addition, the estimates suggest that increased sanctions for the possession of cocaine and marijuana have a negative and statistically significant impact on youth cocaine and marijuana use. However, the magnitude of these estimates implies that very large increases in the monetary fines that can be imposed for first offense possession would be necessary to achieve meaningful reductions in use. Finally, sanctions for the sale, manufacture or distribution of cocaine and marijuana were found to have little impact on youth cocaine and marijuana use.
\end{abstract}

Frank Chaloupka

Department of Economics (M/C 144)

University of Illinois at Chicago

601 South Morgan Street

Chicago, IL 60607-7121

and NBER

fjc@uic.edu

John A. Tauras

Department of Economics (M/C 144)

University of Illinois at Chicago

601 South Morgan Street

Chicago, IL 60607-7121
Michael Grossman

City University of New York Graduate School

33 West 42nd Street

New York, NY 10036

and NBER

MGROSSMA@EMAIL.GC.CUNY.EDU 


\section{Introduction}

From the late 1970 s through the early 1990 s, significant progress was made in reducing illicit drug use in all segments of the population, with perhaps the sharpest reductions occurring among youths and young adults (Bureau of Justice Statistics (BJS), 1992). Based on the Monitoring the Future (MTF) surveys of high school seniors, current use of any illicit drug among youths peaked at 39 percent in 1978 and 1979, while lifetime use of any drug peaked at 65.6 percent in 1981. In 1990, for the first time in these surveys, less than half of high school seniors reported lifetime use of any drug. Lifetime marijuana use fell steadily from a peak of over 60 percent in 1979 to less than 40 percent by 1992 (National Institute on Drug Abuse (NIDA), 1995). Cocaine use by high school seniors peaked later, in the mid- to late-1980s, before beginning to decline. This success led many to conclude that the "War on Drugs" which was intensified during the Reagan and Bush Administrations, was successful. Much of the increased effort focused on interdiction and criminal justice efforts to reduce the supply of and demand for illicit drugs.

In recent years, however, the debate over the costs and benefits of legalizing the use of currently illicit drugs has been revived as illicit drug use, particularly heroin and marijuana use, has increased in the face of increased spending on drug prohibition activities. Particularly troubling is the increased use of drugs by youth (Drug Enforcement Administration (DEA), 1995). In 1996, use of marijuana by 10 th and 12 th grade students increased for the fourth consecutive year, while use by 8th graders rose for the fifth straight year (University of Michigan News and Information Services (UMNIS), 1996). Similarly, reported lifetime use of youth use of any illicit drugs in the MTF surveys has been rising in recent years. This upward trend in teenage drug use is the 
motivation for the Clinton Administration's targeting of youth in its recent National Drug Control Strategies (Office of National Drug Control Policy (ONDCP), 1996 and 1997). This strategy calls for an increase in drug war spending of six percent, to $\$ 16$ billion, in the 1998 fiscal year. Proponents of drug legalization, however, argue that the "War on Drugs" has been ineffective and costly and that the resources currently allocated to the enforcement of drug prohibition could be used much more effectively for drug abuse treatment and education. ${ }^{1}$

This research attempts to inform the drug control policy debate by providing some evidence on the effects of illicit drug prices and legal sanctions for drug possession and sale on youth drug use. Some proponents of legalization argue that illicit drug use is not very responsive to price. If this is true, then the sharp reductions in the prices of illicit drugs that would likely result from legalization would have little impact on drug use. ${ }^{2}$ Opponents of legalization, however, argue that the consequent price reductions and increased availability of drugs would lead to increased rates of use and addiction. This contention is largely based on research on the effects of price on the demand for two widely used legal substances - alcohol and tobacco - showing that the use of these substances, particularly by youths and young adults, is responsive to price. ${ }^{3}$

Given the difficulty in obtaining data on illicit drug use and prices, there are relatively few prior studies on the demand for illicit drugs, particularly demand by youth. This paper uses data on

\footnotetext{
${ }^{1}$ See, for example, the interesting collection of articles by conservative commentator William F. Buckley, Jr., Lindesmith Center Director Ethan A. Nadelman, Baltimore Mayor Kurt Schmoke, former Kansas City and San Jose Chief of Police Joseph D. McNamara, New York City Federal District Court Judge Robert W. Sweet, Syracuse University psychiatry professor Thomas Szasz, and Yale law professor Steven B. Duke in the February 12, 1996 issue of the National Review for arguments in favor of at least some movement towards the legalization of currently illicit drugs.

${ }^{2}$ See Kleiman (1992), Michaels (1988), and Reuter and Kleiman (1986) for some estimates of the impact of legalization on drug prices.

${ }^{3}$ See, for example, the reviews of the literature on alcohol demand by Leung and Phelps (1993) and Grossman, Chaloupka, Saffer, and Laixuthai (1994), and the review of the literature on cigarette demand in the forthcoming U.S. Surgeon General's report (U.S. Department of Health and Human Service (USDHHS), forthcoming).
} 
cocaine and marijuana use by high school seniors taken from the 1982 and 1989 MTF surveys.

Site-specific data on cocaine prices and legal sanctions for the possession and sale, manufacture or distribution of cocaine and marijuana are added to the survey data in order to obtain estimates of the impact of prices and drug control policies on drug use in this high-risk population. This is an age at which many are initiating illicit drug use and where drug abuse and dependence are particularly problematic (BJS, 1992). Thus, understanding the impact of prices and drug control policies on youth drug use is vital to developing policies which will lead to sustained long-run reductions in drug use in all segments of the population.

\section{Prior Studies}

Until recently, very little was known about the impact of prices and drug control policies on the demand for illicit drugs, particularly demand by youth. Nisbet and Vakil (1972) provided an early estimate of the price elasticity of demand ${ }^{4}$ for marijuana, based on an anonymous mail survey of UCLA students, in the range from -0.36 to -1.51 . Two studies by Silverman and his colleagues provided some additional evidence based on heroin prices and crime rates in New York (Brown and Silverman, 1974) and Detroit (Silverman and Spruill, 1977). Brown and Silverman (1974) found that reductions in the price of heroin in New York city led to a drop in what they termed "addict" crimes (property or income producing crimes, such as burglary and robbery), but that prices had no

\footnotetext{
${ }^{4}$ Economists use the term price elasticity of demand to describe the responsiveness of demand to changes in prices. A price elasticity of demand of -0.5 , for example, implies that a ten percent increase in price will reduce demand by five percent. In addition, some studies of drug use (including this one) decompose the price elasticity of demand into two components: the effect of price on whether or not a drug is used, hereafter referred to as the participation elasticity, and the effect of price on the quantity of the drug consumed by drug users, hereafter referred to as the conditional demand elasticity.
} 
impact on non-addict crimes (such as homicide and rape). Similarly, Silverman and Spruill (1977) found that property crime rates in Detroit were positively related to the price of heroin, while other crime rates were not. They used these results to estimate that the price elasticity of demand for heroin is approximately -0.27 .

More recently, DiNardo (1993) used state-aggregated data from the 1977-1987 MTF surveys of high school seniors to examine the impact of cocaine prices on youth cocaine use. Using data on cocaine prices from the DEA's STRIDE data, he found no effect of cocaine prices on youth cocaine use, as measured by the fraction of high school seniors in the state reporting cocaine use in the past month. van Ours (1995) used data on opium consumption in Indonesia during the Dutch colonial period of the 1920's and 1930's. During this period, the Dutch government monopolized the opium market in the then Dutch East Indies (now Indonesia). A nice feature of the monopoly, or opiumregie, was the annual data it gathered on opium consumption, revenues, and the number of users by ethnic group for 22 regions over the period from 1922-1938. Using these data, van Ours estimated a short-run price elasticity of opium demand of -0.7 , with a long-run elasticity of unity. In addition, he obtained estimates of the price elasticity of participation in opium use in the range from -0.3 to -0.4 .

The most recent studies of the price elasticity of illicit drug demand use individual level data. Saffer and Chaloupka (1995) used data on over 49,000 individuals ages 12 years and older surveyed in the 1988, 1990, and 1991 National Household Surveys on Drug Abuse (NHSDA) to estimate the price elasticity of participation in heroin and cocaine use. They estimated a participation elasticity for past month cocaine use of -0.28 , and a comparable elasticity for past month heroin use of -0.94 . In addition, they found that past year cocaine use is somewhat more 
sensitive to price than past month use, while the price elasticity of participation in heroin use in the past year is about the same as for past month use. Similarly, Grossman, Chaloupka, and Brown (1996) used the panel data formed from the MTF baseline surveys of high school seniors conducted from 1976 through 1985 to examine the price elasticity of cocaine demand by young adults. In the context of the Becker and Murphy (1988) model of rational addiction, they estimated a long-run price elasticity of cocaine demand of -1.18 , which is approximately 70 percent larger than their estimated short-run elasticity of -0.71 . In addition, they found positive and significant effects of past and future cocaine use on current use, consistent with the hypothesis of rational addictive behavior.

Relatively more research has been done on the effects of marijuana decriminalization on the demand for marijuana. Oregon, in 1973, was the first state to decriminalize marijuana; by 1978 , 10 other states had followed. Although the possession and use of marijuana in states that have decriminalized is not fully legal, first offense possession is treated as a civil offense rather than a criminal offense in these states. In general, the evidence on the impact of marijuana decriminalization on marijuana use is mixed.

Several studies have found that marijuana decriminalization has no impact on marijuana use. Johnston, Bachman, and O'Malley (1981), using the cross-sectional data from the 1975-1979 MTFF surveys of high school seniors, as well as the data from the first two panels formed from these surveys, found no effect of decriminalization on marijuana use. Similarly, DiNardo and Lemieux (1992) also found no effect of decriminalization on marijuana use using state aggregated data on the fraction of high school seniors reporting any use of marijuana in the past month constructed from the 1977-1987 MTF cross-sections. Likewise, Thies and Register (1993) and 
Pacula (1994) found no effects of marijuana decriminalization on marijuana use using the individual level data on youths and young adults from the National Longitudinal Survey of Youth (NLSY).

Others have found that marijuana decriminalization increases marijuana use. Model (1993) analyzed data on hospital emergency room drug episodes taken from the Drug Abuse Warning Network. She found that marijuana related emergency room episodes are positively related to marijuana decriminalization, leading her to conclude that marijuana use is higher where marijuana is decriminalized. Similarly, Saffer and Chaloupka (1995) using the pooled data from the NHSDA's described above, found that participation in marijuana use is positively and significantly related to marijuana decriminalization. They estimated that decriminalization raises the probability of marijuana use by approximately eight percent.

\section{Data and Methods}

\section{A. Survey Data}

Each year since 1975 , nationally representative samples of between 15,000 and 19,000 high school seniors have been conducted by the University of Michigan's Institute for Social Research (ISR) as part of the Monitoring the Future project. These surveys, described in detail by Johnston, O'Malley, and Bachman (1994), focus on the use of alcohol, tobacco, and illicit drugs among youths. Given the nature of the data being collected, extensive efforts are made to ensure that the data collected are informative. For example, parents are not present during the completion of the 
surveys and are not informed about their child's responses. ${ }^{5}$ The data for this study are taken from the 1982 and 1989 surveys. By special agreement, the ISR provided identifiers for each respondent's county of residence, which allowed site-specific measures of cocaine prices, and penalties for cocaine and marijuana possession and sale, manufacture or distribution to be added to the survey data.

\section{A.1 Dependent Variables}

Four alternative measures for both cocaine and marijuana use are constructed from the categorical data collected in the surveys, two reflecting use in the past year and two reflecting use in the past month for each drug. The surveys obtain information on the frequency of cocaine and marijuana consumption in the year prior to the survey and in the thirty days prior to the survey in the following categories: zero occasions; one to two occasions; three to five occasions; six to nine occasions; ten to nineteen occasions; twenty to thirty-nine occasions; and forty or more occasions. ${ }^{6}$ Over nine percent of the respondents reported cocaine use in the past year, with most of these reporting use on nine or fewer occasions. Past year use of marijuana, however, was much higher. Approximately 38 percent of respondents reported use in the past year, with over eleven percent reporting use on more than 20 occasions. Past month use of both drugs is well below past year use.

\footnotetext{
${ }^{5}$ Given the illicit nature of drug use, one must be concerned about the validity of self-reported data on youth drug use. Johnston and O'Malley (1985) provide a detailed discussion on the validity of the self-reported drug use data collected in the MTF surveys, concluding that the validity and reliability of these data are high. Moreover, they note that the noncoverage of absentees and dropouts has a relatively modest impact on the estimates of prevalence based on these data and has little implication for estimates of trends in prevalence from these data.

${ }^{6}$ In addition, data are collected on the lifetime frequency of consumption as well. However, these data are not used in this study given that no information is provided on the timing of this consumption.
} 
About four percent of the high school seniors surveyed indicate past month use of cocaine, with most reporting five or fewer use occasions. Over 23 percent, however, indicate past month use of marijuana, with almost one-third of these reporting use on ten or more occasions.

Based on the categorical data on frequency of use, four dichotomous indicators of participation in illicit drug use are defined. The first is defined as one for youths reporting any cocaine use in the past year, and is zero otherwise, while the second is a comparable indicator of participation in cocaine use in the past month. Indicators of marijuana participation in the past year and past month are defined in the same manner.

In addition, four "continuous" measures reflecting the number of occasions in the past year and past month each respondent consumed cocaine and marijuana are constructed from the categorical data collected in the surveys. These variables are based on the midpoints of the categorical responses used in the surveys, and take on the following values: $2,4,8,14,30$, and $50{ }^{7}$ While not ideal, these continuous measures will be helpful in estimating the price elasticities of cocaine and marijuana demand by youth. For those reporting positive use, the average number of marijuana use occasions is slightly more than double the average number of cocaine use occasions. In the past year, those using marijuana report use on almost 18 occasions, while cocaine users report use on over eight occasions. Similarly, marijuana users in the past month report an average number of use occasions of just over twelve, while cocaine users in the past month report use on an average of 5.7 occasions.

Table One summarizes the alternative participation rates and average number of cocaine and

\footnotetext{
${ }^{7}$ Alternative values were assigned to the open-ended interval with no appreciable impact on the statistical significance of the estimates or the estimated elasticities. In addition, ordered probit estimates were also obtained for yearly and monthly frequency of cocaine and marijuana use measures constructed from the categorical data. These estimates were consistent with those presented below and are available upon request.
} 
marijuana use occasions by those reporting positive use.

\section{A.2 Independent Variables}

In addition to the measures of cocaine and marijuana use, a number of other variables were constructed from the socioeconomic and demographic data collected in the surveys for inclusion as independent variables in the cocaine and marijuana demand equations. These include: indicators of gender (male and female - omitted), race/ethnicity (white - omitted, black, and other), environment while growing up (urban - omitted, rural, suburban, and mixed), work status (don't work omitted, work less than half-time, and work half-time or more), religiosity (no attendance at religious services - omitted, infrequent attendance, and frequent attendance), family structure (live with both parents - omitted, live alone, live with father only, live with mother only, live with others), marital status (non-single, including engaged, married, or separated - omitted, single), parental education (less than a high school education, high school graduate - omitted, and more than a high school education; defined separately for father and mother), mother's work status while growing up (mother didn't work - omitted, mother worked part-time, and mother worked fulltime), and survey year (defined as one for 1982 and zero for 1989); and continuous measures of age, in years, and average income from all sources (employment, allowances, etc.) in 1982-1984 dollars.

\section{B. Cocaine Prices}


Through a special agreement with the ISR, site specific cocaine prices were added to the survey data. ${ }^{8}$ These price data are constructed from the DEA's System to Retrieve Information from Drug Evidence (STRIDE) database. The DEA provided the data on cocaine prices from 1977 through 1989 and 1991 to the National Bureau of Economic Research for this project. In an effort to apprehend drug dealers, undercover DEA, FBI, and state and local police narcotics officers regularly purchase illicit drugs. The STRIDE database is maintained in part to ensure that the prices offered in these negotiations reflect the actual street prices of these drugs. As Taubman (1991) notes, inaccurate price offers would be likely to make drug dealers suspicious and could potentially endanger agents. The STRIDE database contains information on the date and city of the drug purchase, the total cost of the purchase, the total weight, in grams, of the purchase, and the purity of the drug purchased.

This project uses the same price variable used by Grossman, Chaloupka, and Brown (1996) in their application of the rational addiction model to the demand for cocaine by young adults using the panel data from the Monitoring the Future project. That is, a variation of the procedure used by DiNardo (1993), Caulkins (1994), and Saffer and Chaloupka (1995), is used to estimate the price of one pure gram of cocaine by year and city based on the information contained in the STRIDE database. This is done because total cost rather than price is recorded in the STRIDE database. If total cost were proportional to weight, then price could be computed by dividing total cost by total weight. Unfortunately, however, this is not the case since the larger purchases tend to

\footnotetext{
${ }^{8}$ Unfortunately, marijuana price data of the same quality are not available. Wholesale and retail price data for commercial grade marijuana and sinsemilla, a higher quality strain, were available for a limited number of cities from the DEA's Domestic Cities Report. Using these data required a significant reduction in the sample size. Results for these prices were not consistent. Consequently, the marijuana demand equations employ variables reflecting the penalties for marijuana possession and sale, manufacture or distribution which are available for all sites to capture at least part of the full price of marijuana.
} 
be wholesale purchases where price per unit is lower, all else constant. In addition, differences in purity and imperfect information concerning purity on the part of the purchasers further complicates the matter.

Thus, to obtain an estimate of the price of one pure gram of cocaine, the natural logarithm of the total purchase cost is regressed on the natural logarithm of total weight, the natural logarithm of purity, dichotomous variables for each city and year in the STRIDE database (except one of each), and interactions between the year variables and dichotomous variables for eight of the nine Census of Population regions. This regression uses data on over 25,000 purchases for the 139 cities in the STRIDE data base. Instrumental variables methods are used to address the issue of imperfect information concerning the purity of purchases. Specifically, purity is predicted based on the other regressors described above. To identify the total cost model, the coefficient of the natural logarithm of predicted purity is constrained to equal the coefficient of the natural logarithm of weight. The natural logarithm of the city specific price of one gram of pure cocaine in each year is then estimated as the sum of the intercept, the relevant city dummy coefficient, the relevant year dummy coefficient, and the relevant time-region interaction coefficient. Note that this procedure eliminates variations in price due to variations in weight or purity and that it mitigates the influence of outliers (since the resulting price is akin to a geometric mean). The actual price is obtained by taking the antilog of the variable just described. The real price is then obtained by deflating this variable by the national Consumer Price Index $(1982-1984=1){ }^{9}$

To match the cocaine price data to the survey data, each city from the DEA sample was

\footnotetext{
${ }^{9}$ Several alternative measures of the cocaine price were also created based on alternative specifications of the total cost regression. For example, in one specification purity was treated as exogenous with an unconstrained coefficient. In a second, the time and region interactions were excluded. In a third, purity was excluded from the total cost regression but the predicted value of purity was included as an independent variable in the cocaine demand equations. The estimates presented below were not sensitive to these alternative specifications.
} 
assigned to the smallest of its Metropolitan Statistical Area, Central Metropolitan Statistical Area, or Primary Metropolitan Statistical Area. Counties in this area from the surveys were then assigned that price. If the survey county was not in one of these areas, then a population weighted average of the price from all DEA cities from that state was used.

\section{Cocaine and Marijuana Penalty Variables}

Based on each respondent's state of residence, several variables were added to the survey data reflecting monetary fines and prison terms for the possession and sale, manufacture or distribution of cocaine and marijuana. For marijuana, the simplest of these is a dichotomous indicator equal to one for youths residing in states where marijuana is decriminalized and equal to zero otherwise. Given that decriminalization eliminates criminal sanctions for the possession of small amounts of marijuana, decriminalization is expected to raise the probability of marijuana consumption as well as the amount of marijuana consumed by marijuana users.

In addition to the decriminalization indicator, the statutory minimum and maximum dollar fines for first offense possession of less than one ounce and one pound of marijuana were added to the survey data, as well as the statutory minimum and maximum prison terms for first offense possession of less than one ounce and one pound of marijuana. Thies and Register (1993) note that nearly every state liberalized its treatment of marijuana possession in the 1970s, with all but Nevada reducing conviction for possession from a felony to a misdemeanor. In addition, a number of states also allowed conditional discharge for first-time offenders, requiring that they satisfy other conditions for their criminal case to be dismissed (e.g. participation in a drug education program). 
In some of these states, the fine is waived, while in others it is not waived. These provisions are not fully captured by the decriminalization indicator. Thus, the combination of the decriminalization indicator and the variables reflecting the penalties for possession may more fully capture the legal cost component of the full price of marijuana use. ${ }^{10}$

Similarly, in an effort to capture sanctions affecting the supply of marijuana, eight variables comparable to those added for possession sanctions were added to the survey data for first offense sale, manufacture or distribution of marijuana.

Given the high correlation among the marijuana penalty variables, including more than one or two of them in the marijuana demand equations proved difficult. Consequently, some of the alternative specifications of the marijuana demand models presented below include one or both of the following two variables reflecting penalties for marijuana possession and sale: the midpoint of the range for the dollar fine that could be applied for the possession of less than one ounce of marijuana; and the midpoint of the range for the dollar fine that could be applied for the sale, manufacture, or distribution of less than one ounce of marijuana. ${ }^{11}$

For cocaine, eight variables reflecting penalties for the possession and sale of cocaine were added to the 1989 survey data (unfortunately, these variables were not available for 1982). These variables reflect the statutory minimum and maximum dollar fines and prison terms for first offense cocaine possession and sale, manufacture or distribution. As with the marijuana penalty variables, the cocaine penalty variables were highly correlated. Thus, some of the alternative specifications of

\footnotetext{
${ }^{10}$ The full price of marijuana includes the monetary price, the expected legal sanctions associated with using marijuana, the time spent obtaining marijuana, and other non-monetary costs of marijuana use.

${ }^{11}$ In general, the results from alternative specifications that included other measures of the penalties for marijuana possession and sale were similar to those presented below. Perhaps the most notable difference was that the variables reflecting monetary fines performed somewhat better than those measuring prison terms.
} 
the cocaine demand models presented below include the midpoint of the dollar fine which could be applied for the possession of cocaine and, in others, the midpoint of the dollar fine which could be applied for the sale, manufacture, or distribution of cocaine. ${ }^{12}$

Marijuana fines are measured in 1982-1984 dollars. The data on the penalties for marijuana possession and sale, as well as for the decriminalization of marijuana come from the Bureau of Justice Statistic's annual Sourcebook of Criminal Justice Statistics. Additional data on the sanctions related to marijuana, as well as for those related to cocaine, come from the 1988 and 1991 volumes of the National Criminal Justice Association's A Guide to State Controlled Substance Acts.

While these penalty measures provide some information on the legal sanctions associated with the possession and sale, manufacture and distribution of marijuana and cocaine, they are not ideal. In theory, the expected legal costs associated with possession and sale will influence behavior, where the expected costs depend positively on the probability of apprehension, the probability of conviction, and the penalties imposed upon conviction. While the sanction data may partially capture the penalties that are imposed upon conviction, good data were not available on the probabilities of arrest and conviction. If these probabilities are very small, then it is unlikely that the fines that can be imposed upon conviction will have a large impact on youth drug use. ${ }^{13}$

\section{Econometric Methods}

\footnotetext{
${ }^{12}$ As with marijuana, the results from models using alternative measures of the penalties for cocaine possession and/or sale were similar to those presented below.

${ }^{\mathrm{F}_{\mathrm{r}}} \mathrm{r}$ example, consider the regression model $\mathrm{y}=\mathrm{bpf}+$ other variables, where $\mathrm{p}$ is the probability of arrest and conviction and $f$ is the fine imposed upon conviction (i.e. pf is the expected fine). If $p$ does not vary among states or cities, then the estimated coefficient on the fine variable is $b p$. Thus, if $p$ is very small, the estimated coefficient on the fine will be very small.
} 
Given the limited nature of the dependent variables, ordinary least squares techniques are not appropriate. Instead, a two-part model of youth demand for cocaine and marijuana is estimated based on the model developed by Cragg (1971). In the first step, probit methods are used to estimate participation in cocaine and marijuana use equations. In the second step, ordinary least squares methods are used to estimate the number of cocaine and marijuana use occasions by users, where the dependent variables are the natural logarithms of the "continuous" measures of use. The same set of independent variables is included in both equations.

\section{Results}

The estimated price and penalty coefficients from alternative specifications of youth cocaine demand are presented below in Table Two. Panels A and B present the estimated coefficients for cocaine price obtained from the combined 1982 and 1989 survey data for past year and past month cocaine use, respectively. Panels C and D contain comparable estimates for the 1989 sample for models which add the monetary fines for cocaine possession and sale, manufacture or distribution to the models in Panels A and B.

Similarly, the estimated marijuana decriminalization and penalty coefficients from alternative specifications of youth marijuana demand are shown in Table Four. Panels A and B contain estimates for models of marijuana demand in the past year and past month, respectively, which contain the decriminalization indicator as a measure of the marijuana price. Panels C and D contain comparable estimates for models that replace the decriminalization indicator with the monetary fines for possession and sale, manufacture or distribution of marijuana. Panels $\mathrm{E}$ and $\mathrm{F}$ 
include the estimates from models that include both the decriminalization indicator and the two fine variables.

Each table contains estimates from two alternative models for both participation and conditional demand. The first contains a relatively limited set of independent variables consisting of the indicators of gender, race/ethnicity, environment while growing up, work status, religiosity, and year (where appropriate) and the continuous measures of age and real weekly income. The second model adds the indicators of family structure, marital status, parents' education, and mother's work status while growing up.

\section{A. Cocaine Demand}

The real price of cocaine has a negative and statistically significant impact on cocaine demand in all eight of the equations estimated using the combination of the 1982 and 1989 survey. In addition, the cocaine price has a negative and significant impact at the five percent level in three of the models and at the ten percent level in the fourth model for past year cocaine use based on the 1989 data. While negative, the estimated effect of the cocaine price on past month participation in cocaine use for the 1989 model are not significant at conventional levels. Finally, for the 1989 sample, the estimated effect of price on cocaine use occasions by youth cocaine users is negative and significant in both models. These estimates provide strong evidence that youth cocaine demand is inversely related to price. These findings are consistent with those obtained for young adults by Grossman, Chaloupka, and Brown (1996), as well as for Saffer and Chaloupka's (1995) sample of persons ages 12 years and older. 
Table Three contains estimated price elasticities of participation in cocaine use, the number of cocaine use occasions by users, and the total price elasticity of cocaine demand based on the results from the two-part models of cocaine demand presented in Table Two. The estimates from the 1982 and 1989 survey data suggest that much of the impact of price on youth cocaine use is on the decision to use cocaine, with a relatively smaller impact on the number of occasions cocaine is used by users. The average estimated price elasticity of participation in the past year, based on the 1982 and 1989 data, is -0.89 , while the comparable estimate for participation in past month cocaine use is -0.98 . Similarly, the average of the estimates of the price elasticity for cocaine use occasions by young cocaine users is -0.40 for use in the past year and -0.45 for use in the past month. Thus, the average overall price elasticities of youth cocaine demand are -1.28 and -1.43 based on the measures of use in the past year and past month, respectively.

The estimates of the participation elasticities, based on the less statistically significant results from the models using the 1989 data only, are less than half those obtained from the larger sample. However, the estimates for the price elasticity for cocaine use occasions by users are quite similar, with an average elasticity of -0.34 for use in the past year and -0.49 for use in the past month. These estimates suggest that the price elasticity of participation in cocaine use is falling over the period covered by the data, but that the effect of price on the number of occasions cocaine is used by young users is unchanged.

The estimated participation elasticities are well above those obtained by Saffer and Chaloupka (1995) in their sample consisting largely of adults. This is consistent with much of the evidence on the price elasticity of cigarette demand which finds that youths are generally much more sensitive to price than adults (USDHHS, forthcoming). Thus, these estimates suggest that 
changes in drug control policies that raise the price of cocaine will have a larger impact on youth cocaine use than they will on cocaine use among adults.

Turning to the effects of legal sanctions for cocaine possession on youth cocaine use, the estimates for the midpoint of the monetary fine which can be imposed for first offense cocaine possession are negative and statistically significant in all models for past year or past month participation in cocaine use. However, the variable reflecting fines for possession has a negative but statistically insignificant impact on the use of cocaine by cocaine users. Thus, these estimates suggest that increases in the legal sanctions for cocaine possession would be successful in reducing the number of youths using cocaine but would have less of an impact on the frequency of use by young cocaine users. For example, the average estimated elasticity for youth participation in cocaine use in the past year and past month with respect to fines for cocaine possession is -0.035 . Thus, a doubling of the fines of cocaine possession would lead to about a three and one-half percent reduction in the probability that a youth uses cocaine.

Finally, the impact on youth cocaine use of the variable reflecting penalties for the sale, manufacture or distribution of cocaine was generally insignificant. Indeed, in many cases this variable had a positive impact on youth cocaine use, contrary to expectations. Penalties for supplying cocaine were included in an attempt to capture the impact of availability on youth cocaine use, with the expectation that if these penalties were effective in deterring the sale of cocaine, availability would be reduced, leading to a reduction in cocaine use. It may be that these penalties are being captured by the cocaine price and/or fines for possession variable. That is, if high penalties for cocaine sale reduce supply, then cocaine prices will rise. As the estimates indicate, the higher prices will then reduce youth cocaine use. Alternatively, it may be that as the result of plea- 
bargaining, many arrests for sale are penalized at the levels used for possession. Thus, the negative and significant effects of the fine for possession might capture, in part, the effects of reduced availability.

\section{B. Marijuana Demand}

The indicator for marijuana decriminalization has a positive and statistically significant effect in the four models using past year participation in marijuana use as the dependent variable. However, the decriminalization indicator is generally insignificant and/or negative for the two measures of marijuana use in the past month as well as for the measure of past year marijuana use occasions by users. These estimates are, to some extent, consistent with the mixed findings from past research on the impact of marijuana decriminalization on marijuana use. Simulations based on the estimates from the past year participation in marijuana use equations suggest that decriminalizing marijuana in all states would have raised the number of youths using marijuana in the past year by four to five percent compared to the number when marijuana is criminalized in all states. Decriminalization, however, appears to have no effect on either the probability of past month marijuana use or on the number of occasions young marijuana users consume marijuana in the past year or past month.

The variable capturing penalties for marijuana possession, however, has a negative and statistically significant impact on both measures of participation in marijuana use as well as on both measures of the number of occasions marijuana is used by users in all models in which it enters. These estimates suggest that increases in the fines levied for first offense marijuana possession 
would reduce both the probability that a youth uses marijuana as well as the number of occasions marijuana is used by users. However, as was described for cocaine above, even relatively large increases in penalties would lead to relatively small reductions in youth marijuana use. For example, the average estimated elasticities of participation in marijuana use in the past year and past month with respect to fines for marijuana possession are -0.008 and -0.007 , respectively, with the comparable estimates for the number of marijuana use occasions by users of -0.003 and -0.010 . Thus, doubling the fines which can be imposed for marijuana possession would reduce the probability that a youth uses marijuana by less than one percent, while reducing overall youth marijuana use by about one and one-half percent.

The variable reflecting penalties for the sale, manufacture or distribution of marijuana, however, has a positive and generally insignificant effect on the alternative measures of youth marijuana use. As with cocaine, these estimates suggest that sharp increases in the penalties for marijuana sale would have little, if any, impact on youth marijuana use. ${ }^{14}$

\section{Socioeconomic/Demographic Determinants of Youth Cocaine and Marijuana Use ${ }^{15}$}

Young men are significantly more likely than young women to consume cocaine and marijuana. Similarly, young male users consume marijuana on more occasions than young female users. In general, however, there are few differences in the number of occasions cocaine is consumed by young male and female users.

\footnotetext{
${ }^{14}$ Unlike the case of cocaine, where the money price was being held constant, the penalty for sale of marijuana was
expected to partially capture the effects of money price on demand.

${ }^{15}$ In the interest of space, these estimates are not included in the tables of results, but are available upon request.
} 
With respect to race and ethnicity, young blacks are least likely to consume cocaine and marijuana and consume on fewer occasions, while young whites are most likely to consume and are the heaviest consumers. Among past month cocaine users, however, young blacks are the heaviest consumers. There are few significant differences in cocaine consumption between whites and nonblack individuals of other races, but whites are significantly more likely to use marijuana and to consume marijuana on more occasions.

No consistent patterns emerge with respect to age and marijuana or cocaine use among high school seniors.

Youths with higher real weekly incomes are significantly more likely to consume both cocaine and marijuana as well as to consume more frequently. The average estimated total income elasticity of youth marijuana demand is 0.26 , with approximately half of the effect of income on the decision to use marijuana and the remainder on the number of occasions marijuana is consumed by users. Youth cocaine demand is relatively more income elastic, with an average estimated overall income elasticity of 0.55 from the two-part models using the combined 1982 and 1989 surveys. Approximately two-thirds of the effect of income on youth cocaine demand is on the decision to use cocaine, with the remainder on the number of occasions cocaine is consumed by users,

Youths who were raised in rural areas are significantly less likely to use either cocaine or marijuana than those raised in suburban or urban areas. There are no apparent differences in the probability of using cocaine for youths raised in urban or suburban areas, although those raised in suburban areas are more likely to be regular marijuana users. There are no consistent differences in the effects of environment while growing up on the number of occasions cocaine or marijuana are 
consumed by users.

Holding income constant, employed youths are generally less likely to participate in cocaine use and, for users, consume on fewer occasions than youths who are not working. A different pattern emerges with respect to youth marijuana use, where employed youths, particularly those working more than half time, are more likely to be marijuana users. Among marijuana users, however, employed youths consume on fewer occasions than youths that are not working.

Religiosity, as reflected by frequency of attendance at religious services, has a significant impact on youth cocaine and marijuana use. Youths indicating that they attend services frequently are much less likely to use either cocaine or marijuana and to consume on fewer occasions than those who attend less frequently, while youths who do not attend services are most likely to use both substances and to consume most often.

Similarly, family structure appears to be an important determinant of youth participation in cocaine and marijuana use. Youths living with both parents are significantly less likely to use either substance than other youths, while those living alone are most likely to use. The same pattern appears to apply to the number of marijuana use occasions by marijuana users. Among cocaine users, however, family structure appears to have little impact on the number of cocaine use occasions.

In general, parents' education appears to have little impact on youth cocaine or marijuana use. The most consistently significant, somewhat surprising difference that emerges is that youths with less educated mothers are generally less likely to use either cocaine or marijuana and to consume less often than those with more educated mothers.

Similarly, youth marital status, as reflected by the indicator for single youths (excludes 
engaged, married, or separated youths) has little impact on youth cocaine or marijuana demand. This is not surprising given the relatively small number of non-single high school seniors in the survey data.

Youths whose mothers worked while they were growing up are more likely to participate in marijuana use, with those whose mothers worked full-time more likely to use marijuana than those whose mothers worked part-time. Maternal work status while young, however, does not appear to affect the number of occasions marijuana is consumed by users. Similarly, maternal work status appears to have no impact on youth cocaine demand.

Finally, the dichotomous indicator for youths surveyed in 1982 is positive and significant in all equations, indicating that youth cocaine and marijuana use declined significantly between 1982 and 1989. In recent years, however, this downward trend appears to have been reversed, particularly for youth marijuana use (UMNIS, 1996).

\section{Discussion}

The results presented above provide consistent evidence that youth cocaine use is sensitive to price. Based on the results from the combined 1982 and 1989 Monitoring the Future surveys of high school seniors, a ten percent increase in the price of cocaine would reduce the probability of youth cocaine use by nine to ten percent, while reducing the number of occasions cocaine users consume cocaine by over four percent. The estimated price elasticity of youth past year participation in cocaine use is more than double Saffer and Chaloupka's (1995) estimate based on a sample consisting mostly of adults. Moreover, the estimated price elasticity of youth past month 
participation in cocaine use is more than three times Saffer and Chaloupka's comparable estimate. This confirms what many have found when comparing the price sensitivity of youth and adult demands for two licit substances - alcohol and cigarettes - that youth substance use is more sensitive to price than is adult substance use.

In addition, the estimates presented above suggest that increased sanctions for the possession of cocaine and marijuana have a negative and statistically significant impact on cocaine and marijuana use. However, the magnitude of these estimates implies that very large increases in the monetary fines that can be applied for first offense possession would be necessary to achieve substantial reductions in use. For example, doubling the fines that could be applied for cocaine possession during the time period covered by these data would have reduced the probability of youth cocaine use by less than four percent. A similar increase in the fines for marijuana possession would have reduced the probability of youth marijuana use by less than one percent. Similarly, marijuana decriminalization is estimated to raise the probability of past year marijuana use by about four to five percent, but is not found to impact either the probability of more recent marijuana use or the number of occasions users consume marijuana.

Less effective were increased sanctions for the sale, manufacture or distribution of cocaine and marijuana. Increases in these penalties were expected to reduce the availability of cocaine and marijuana, increase their full prices, and, consequently, reduce the use of cocaine and marijuana. In general, higher sanctions for the sale, manufacture or distribution of cocaine were not found to reduce youth cocaine use. The same was true for the sanctions that could be applied for the sale, manufacture, or distribution of marijuana.

Clearly, these results are not sufficient to resolve the current debate over the direction of 
drug control policy in the U.S.. Nevertheless, these findings have important implications for this debate. For example, the finding the youth illicit drug use is quite sensitive to price implies that the substantial reductions in illicit drug prices which would almost certainly result from partial or full drug legalization would lead to significant increases in the number of youths consuming illicit drugs, as well as in many of the consequences of youth drug use. 


\section{Literature Cited}

Becker, Gary S., and Kevin M. Murphy, "A Theory of Rational Addiction, " Journal of Political Economy, 96(4): 675-700, 1988.

Brown, George F., and Lester P. Silverman, "The Retail Price of Heroin: Estimation and Applications," Journal of the American Statistical Association, 347(69): 595-606, 1974.

Buckley, William F., Jr., Ethan A. Nadelman, Kurt Schmoke, Joseph D. McNamara, Robert W. Sweet, Thomas Szasz, and Steven B. Duke, "The War on Drugs is Lost," National Review, February 12, 1996, 34-48,

Bureau of Justice Statistics, A National Report: Drugs, Crime, and the Justice System. Washington, D.C.: Bureau of Justice Statistics, Office of Justice Programs, U.S. Department of Justice, 1992.

Bureau of Justice Statistics, Sourcebook of Criminal Justice Statistics. Washington, D.C.: Bureau of Justice Statistics, Office of Justice Programs, U.S. Department of Justice, various years.

Caulkins, Jonathan P., Developing Price Series for Cocaine. Santa Monica, CA: Rand Corporation, 1994.

Cragg, John G., "Some Statistical Models for Limited Dependent Variables with Application to the Demand for Durable Goods, " Econometrica, 39(5): 829-844, 1971.

DiNardo, John, "Law Enforcement, the Price of Cocaine, and Cocaine Use," Mathematical and Computer Modeling, 17(2): 53-64, 1993.

DiNardo, John, and Thomas Lemieux, "Alcohol, Marijuana, and American Youth: The Unintended Effects of Government Regulation," National Bureau of Economic Research Working Paper No. 4212, 1992.

Drug Enforcement Administration, Speaking Out Against Drug Legalization. Washington, D.C.: Drug Enforcement Administration, U.S. Department of Justice, 1995.

Drug Enforcement Administration, The Domestic Cities Report: The Illicit Drug Situation in Nineteen Metropolitan Areas. Washington, D.C.: Drug Enforcement Administration, U.S. Department of Justice, various years.

Grossman, Michael, Frank J. Chaloupka, Henry Saffer, and Adit Laixuthai, "Alcohol Price Policy and Youths: A Summary of Economic Research," Journal of Research on Adolescence, 4(2): 347 364, 1994.

Grossman, Michael, Frank J. Chaloupka, and Charles C. Brown, "The Demand for Cocaine by Young Adults: A Rational Addiction Approach," National Bureau of Economic Research Working 
Paper Number 5713, August, 1996.

Johnston, Lloyd D., and Patrick M. O'Malley, "Issues of Validity and Population Coverage in Student Surveys of Drug Use," in Self-Report Methods of Estimating Drug Use: Meeting Current Challenges to Validity, edited by Beatrice A. Rouse, Nicholas J. Kozel, and Louise G. richards. Rockville, MD: National Institute on Drug Abuse, Alcohol, Drug Abuse, and Mental Health Administration, Public Health Service, U.S. Department of Health and Human Services, 1985.

Johnston, Lloyd D., Patrick M. O'Malley, and Jerald D. Bachman, "Marijuana Decriminalization: The Impact on Youth, 1975-1980," Monitoring the Future Occasional Paper No. 13, Institute for Social Research, University of Michigan, 1981.

Johnston, Lloyd D., Patrick M. O'Malley, and Jerald D. Bachman, National Survey Results on Drug Use from the Monitoring the Future Study, 1975-1993. Washington, D.C.: U.S.

Government Printing Office, 1994.

Kleiman, Mark A.R., Against Excess: Drug Policy for Results., New York: Basic Books, 1992.

Leung, Siu Fai, and Charles E. Phelps, "'My Kingdom for a Drink . . .?': A Review of Estimates of the Price Sensitivity of the Demand for Alcoholic Beverages," in Economics and the Prevention of Alcohol-Related Problems, edited by Gregory Bloss and Michael Hilton. Rockville, MD: National Institute on Alcohol Abuse and Alcoholism, National Institutes of Health, Public Health Service, U.S. Department of Health and Human Services, 1993.

Michaels, Robert J., "The Market for Heroin Before and After Legalization," in Dealing With Drugs: Consequences of Government Control, edited by Ronald Hamowy. Lexington, MA: Lexington Books, D.C. Heath and Company, 1988.

Model, Karyn E., "The Effect of Marijuana Decriminalization on Hospital Emergency Room Drug Episodes: 1975-1978," Journal of the American Statistical Association, 88(423): 737-747, 1993.

National Criminal Justice Association, A Guide to State Controlled Substance Acts. Washington, D.C.: National Criminal Justice Association, Bureau of Justice Assistance, U.S. Department of
Justice, 1988.

National Criminal Justice Association, A Guide to State Controlled Substance Acts. Washington, D.C.: National Criminal Justice Association, Bureau of Justice Assistance, U.S. Department of
Justice, 1991.

National Institute on Drug Abuse, Annual Survey Shows Increases in Tobacco and Drug Use by Youth. Washington, D.C.: National Institute on Drug Abuse, 1995.

Nisbet, Charles T., and Firouz Vakil, "Some Estimates of Price and Expenditure Elasticities of Demand for Marijuana Among U.C.L.A. Students," Review of Economics and Statistics, 54(4):
473-475, 1972 . 
Office of National Drug Control Policy, National Drug Control Strategy. Washington, D.C.: Office of National Drug Control Policy, Executive Office of the President, 1996.

Office of National Drug Control Policy, Press Release: National Drug Control Strategy. Washington, D.C.: Office of National Drug Control Policy, Executive Office of the President,

Pacula, Rosalie Liccardo, "Can Increasing the Beer Tax Reduce Marijuana Consumption?" manuscript, Department of Economics, Duke University, 1994.

Reuter, Peter, and Mark A.R. Kleiman, "Risks and Prices: An Economic Analysis of Drug Enforcement," in Crime and Justice, edited by Michael H. Tonry and Norval Morris. Chicago: University of Chicago Press, 1986.

Saffer, Henry, and Frank J. Chaloupka, "The Demand for Illicit Drugs, " National Bureau of Economic Research Working Paper No. 5238, 1995.

Silverman, Lester P., and Nancy L. Spruill, "Urban Crime and the Price of Heroin," Journal of Urban Economics, 4(1): 80-103, 1977.

Taubman, Paul, "Externalities and Decriminalization of Drugs," in Drug Policy in the United States, edited by Melvyn B. Krauss and Edward P. Lazear. Stanford, CA: Hoover Institution Press, 1991.

Thies, C.F., and C.A. Register, "Decriminalization of Marijuana and the Demand for Alcohol, Marijuana, and Cocaine," The Social Science Journal, 30(4): 385-399, 1993.

U.S. Department of Health and Human Services, The Context for Change: The Efficacy of Interventions for Smoking Prevention and Control. A Report of the U.S. Surgeon General, Atlanta: U.S. Department of Health and Human Services, Public Health Service, Centers for Disease Control and Prevention, National Center for Chronic Disease Prevention and Health Promotion, Office on Smoking and Health, forthcoming.

University of Michigan News and Information Services, "Monitoring the Future Study Press Release, December 19, 1996," Ann Arbor: University of Michigan News and Information
Services, 1996.

van Ours, Jan C., "The Price Elasticity of Hard Drugs: The Case of Opium in the Dutch East Indies, 1923-1938," Journal of Political Economy, 103(2): 261-279, 1995. 
Table One

Youth Cocaine and Marijuana Use

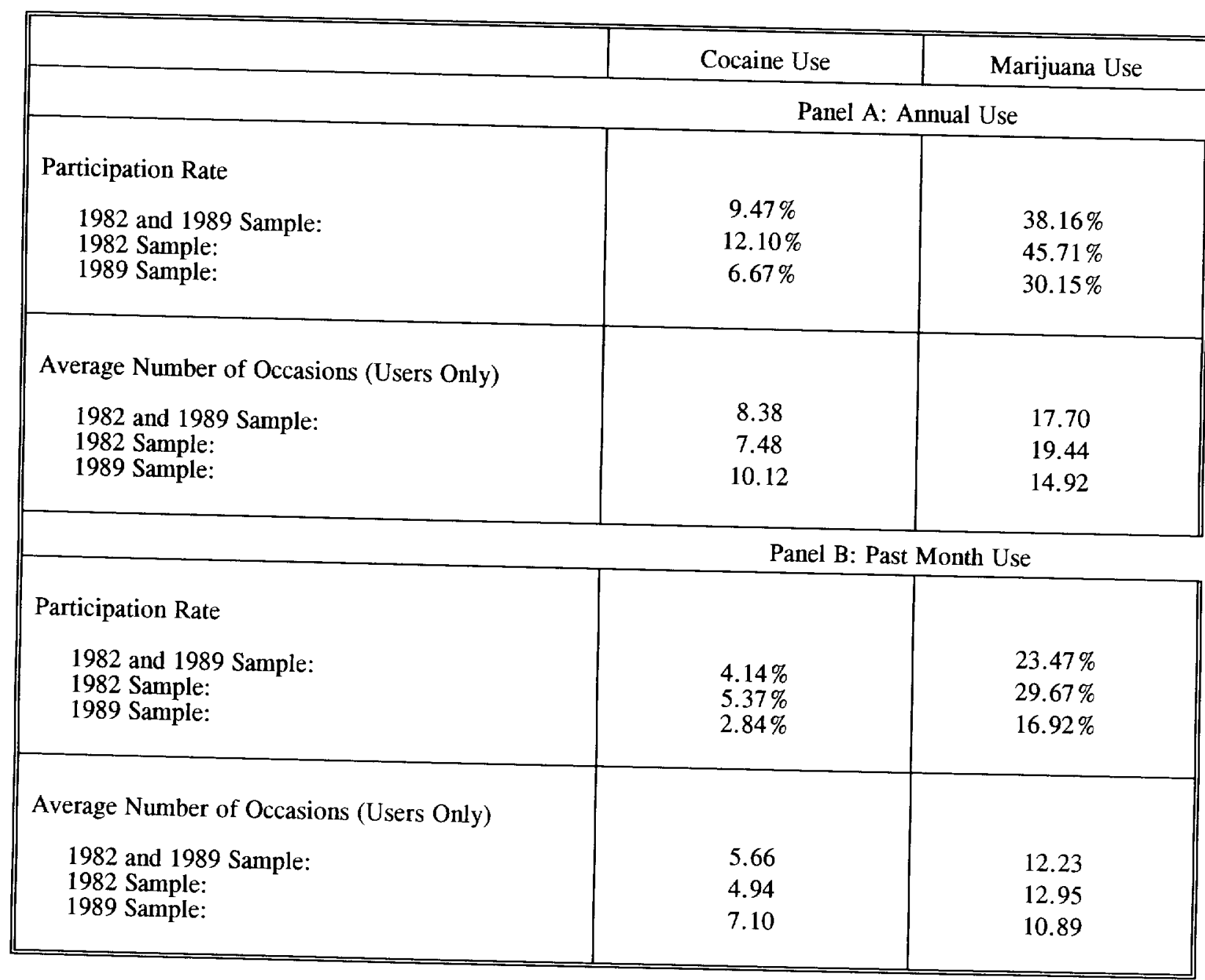


Table Two

Two-Part Models of Youth Cocaine Use

\begin{tabular}{|c|c|c|c|c|}
\hline \multirow[b]{2}{*}{ Variable } & \multicolumn{2}{|c|}{ Participation in Cocaine Use } & \multicolumn{2}{|c|}{$\begin{array}{c}\text { Cocaine Use Occasions by Cocaine } \\
\text { Users"* }\end{array}$} \\
\hline & Model One & Model Two & Model One & Model Two \\
\hline \multicolumn{5}{|c|}{ Panel A: Past Year Use, 1982 and 1989 Sample } \\
\hline Price & $\begin{array}{c}-0.002 \\
(-11.10) \\
\end{array}$ & $\begin{array}{c}-0.002 \\
(-10.84) \\
\end{array}$ & $\begin{array}{l}-0.002 \\
(-4.12) \\
\end{array}$ & $\begin{array}{r}-0.002 \\
(-4.03) \\
\end{array}$ \\
\hline \multicolumn{5}{|c|}{ Panel B: Past Month Use, 1982 and 1989 Sample } \\
\hline Price & $\begin{array}{l}-0.003 \\
(-8.58) \\
\end{array}$ & $\begin{array}{l}-0.002 \\
(-8.41) \\
\end{array}$ & $\begin{array}{l}-0.002 \\
(-3.83) \\
\end{array}$ & $\begin{array}{r}-0.002 \\
(-3.72) \\
\end{array}$ \\
\hline \multicolumn{5}{|c|}{ Panel C: Past Year Use, 1989 Sample } \\
\hline Price & $\begin{array}{r}-0.001 \\
(-1.68) \\
\end{array}$ & $\begin{array}{r}-0.001 \\
(-1.52) \\
\end{array}$ & $\begin{array}{l}-0.003 \\
(-1.70) \\
\end{array}$ & $\begin{array}{l}-0.003 \\
(-1.77) \\
\end{array}$ \\
\hline $\begin{array}{l}\text { Fine for Cocaine } \\
\text { Possession }\end{array}$ & $\begin{array}{c}-0.0000008 \\
(-2.07)\end{array}$ & $\begin{array}{c}-0.0000008 \\
(-2.04)\end{array}$ & $\begin{array}{c}0.0000002 \\
(0.24)\end{array}$ & $\begin{array}{c}0.00000006 \\
(0.07)\end{array}$ \\
\hline $\begin{array}{l}\text { Fine for Cocaine } \\
\text { Sale }\end{array}$ & $\begin{array}{c}-0.00000006 \\
(-0.26) \\
\end{array}$ & $\begin{array}{c}-0.00000004 \\
(-0.18) \\
\end{array}$ & $\begin{array}{c}0.0000004 \\
(0.72) \\
\end{array}$ & $\begin{array}{c}0.0000004 \\
(0.75)\end{array}$ \\
\hline \multicolumn{5}{|c|}{ Panel D: Past Month Use, 1989 Sample } \\
\hline Price & $\begin{array}{l}-0.001 \\
(-1.10) \\
\end{array}$ & $\begin{array}{l}-0.001 \\
(-1.04) \\
\end{array}$ & $\begin{array}{l}-0.004 \\
(-1.73) \\
\end{array}$ & $\begin{array}{l}-0.004 \\
(-1.80) \\
\end{array}$ \\
\hline $\begin{array}{l}\text { Fine for Cocaine } \\
\text { Possession }\end{array}$ & $\begin{array}{c}-0.0000007 \\
(-1.43)\end{array}$ & $\begin{array}{c}-0.0000007 \\
(-1.44)\end{array}$ & $\begin{array}{c}-0.0000009 \\
(-0.93) \\
\end{array}$ & $\begin{array}{c}-0.000001 \\
(-1.07) \\
\end{array}$ \\
\hline $\begin{array}{l}\text { Fine for Cocaine } \\
\text { Sale }\end{array}$ & $\begin{array}{c}0.0000004 \\
(1.26)\end{array}$ & $\begin{array}{c}0.0000004 \\
(1.31)\end{array}$ & $\begin{array}{c}0.0000006 \\
(1.10)\end{array}$ & $\begin{array}{c}0.0000006 \\
(1.09)\end{array}$ \\
\hline
\end{tabular}

year (where appropriate), year (where appropriate), the continuous measures of age and real weekly income, and an intercept. Model Two adds "*Acators of family structure, marital status, parents' education, and mother's work status while growing up.

Asymptotic $t$-ratios are in the parentheses. The critical value for the t-ratios are $2.58(2.33), 1.96(1.64)$, and
$1.64(1.28)$ at the one, five, and ten perant test. All equations, based on a Chi-square significance levels respectively, based on a two-tailed (one-tailed) significance level.

"'t-ratios are in the parentheses. The critical value for the t-ratios are $2.58(2.33), 1.96(1.64)$, and 1.64 (1.28) at the one, five, and ten percent significance levels respectively, based on a two-tailed (one-tailed) test. All equations, based on an $\mathrm{F}$ test are significant at the one percent level. 
Table Three

Estimated Price Elasticities of Youth Cocaine Demand

\begin{tabular}{|l|c|c|}
\hline & Model One & Model Two \\
\hline & \multicolumn{2}{|c|}{ Panel A: Past Year Use, 1982 and 1989 Sample } \\
\hline Participation & -0.902 & -0.875 \\
\hline Conditional Use & -0.400 & -0.393 \\
\hline Total & -1.302 & -1.268 \\
\hline & Panel B: Past Month Use, 1982 and 1989 Sample \\
\hline Participation & -0.996 & -0.963 \\
\hline Conditional Use & -0.459 & -0.447 \\
\hline Total & -1.452 & -1.410 \\
\hline & \multicolumn{2}{|c|}{ Panel C: Past Year Use, 1989 Sample } \\
\hline Participation & -0.268 & -0.239 \\
\hline Conditional Use & -0.330 & -0.347 \\
\hline Total & -0.598 & -0.586 \\
\hline & \multicolumn{2}{|c|}{ Panel D: Past Month Use, 1989 Sample } \\
\hline Participation & -0.255 & -0.235 \\
\hline Conditional Use & -0.477 & -0.494 \\
\hline Total & -0.732 & -0.729 \\
\hline
\end{tabular}
"Estimated elasticities are based on the results from the two-part models of youth cocaine use contained in Table
Two. 
Table Four

Two-Part Models of Youth Marijuana Use*

\begin{tabular}{|c|c|c|c|c|}
\hline \multirow[b]{2}{*}{ Variable } & \multicolumn{2}{|c|}{ Participation in Marijuana Use ${ }^{* *}$} & \multicolumn{2}{|c|}{$\begin{array}{c}\text { Marijuana Use Occasions by Marijuana } \\
\text { Users }^{* * *}\end{array}$} \\
\hline & Model One & Model Two & Model One & Model Two \\
\hline \multicolumn{5}{|c|}{ Panel A: Past Year Use } \\
\hline $\begin{array}{l}\text { Marijuana } \\
\text { Decriminalization }\end{array}$ & $\begin{array}{c}0.05 \\
(2.74) \\
\end{array}$ & $\begin{array}{c}0.04 \\
(2.40) \\
\end{array}$ & $\begin{array}{l}-0.026 \\
(-0.96) \\
\end{array}$ & $\begin{array}{r}-0.028 \\
(-1.05) \\
\end{array}$ \\
\hline \multicolumn{5}{|c|}{ Panel B: Past Month Use } \\
\hline $\begin{array}{l}\text { Marijuana } \\
\text { Decriminalization }\end{array}$ & $\begin{array}{l}0.013 \\
(0.67) \\
\end{array}$ & $\begin{array}{l}0.009 \\
(0.45) \\
\end{array}$ & $\begin{array}{l}-0.054 \\
(-1.75)\end{array}$ & $\begin{array}{l}-0.054 \\
(-1.73)\end{array}$ \\
\hline \multicolumn{5}{|c|}{ Panel C: Past Year Use } \\
\hline $\begin{array}{l}\text { Fine for } \\
\text { Possession }\end{array}$ & $\begin{array}{c}-0.0004 \\
(-2.67) \\
\end{array}$ & $\begin{array}{l}-0.0005 \\
(-2.77) \\
\end{array}$ & $\begin{array}{l}-0.0004 \\
(-1.52) \\
\end{array}$ & $\begin{array}{l}-0.0004 \\
(-1.57) \\
\end{array}$ \\
\hline Fine for Sale & $\begin{array}{l}0.0001 \\
(0.99) \\
\end{array}$ & $\begin{array}{c}0.0001 \\
(0.99) \\
\end{array}$ & $\begin{array}{l}0.0003 \\
(1.28) \\
\end{array}$ & $\begin{array}{l}0.0003 \\
(1.27)\end{array}$ \\
\hline \multicolumn{5}{|c|}{ Panel D: Past Month Use } \\
\hline $\begin{array}{l}\text { Fine for } \\
\text { Possession }\end{array}$ & $\begin{array}{l}-0.0004 \\
(-2.39) \\
\end{array}$ & $\begin{array}{c}-0.0004 \\
(-2.46) \\
\end{array}$ & $\begin{array}{l}-0.0007 \\
(-2.29) \\
\end{array}$ & $\begin{array}{l}-0.0007 \\
(-2.34) \\
\end{array}$ \\
\hline Fine for Sale & $\begin{array}{l}0.0002 \\
(1.02) \\
\end{array}$ & $\begin{array}{c}0.0002 \\
(0.99) \\
\end{array}$ & $\begin{array}{c}0.0005 \\
(2.04) \\
\end{array}$ & $\begin{array}{l}0.0005 \\
(2.08) \\
\end{array}$ \\
\hline \multicolumn{5}{|c|}{ Panel E: Past Year Use } \\
\hline $\begin{array}{l}\text { Marijuana } \\
\text { Decriminalization }\end{array}$ & $\begin{array}{l}0.048 \\
(2.59) \\
\end{array}$ & $\begin{array}{c}0.041 \\
(2.20) \\
\end{array}$ & $\begin{array}{l}-0.022 \\
(-0.81) \\
\end{array}$ & $\begin{array}{l}-0.025 \\
(-0.92) \\
\end{array}$ \\
\hline $\begin{array}{l}\text { Fine for } \\
\text { Possession }\end{array}$ & $\begin{array}{l}-0.0005 \\
(-2.91) \\
\end{array}$ & $\begin{array}{l}-0.0005 \\
(-2.98) \\
\end{array}$ & $\begin{array}{l}-0.0004 \\
(-1.43) \\
\end{array}$ & $\begin{array}{c}-0.0004 \\
(-1.47) \\
\end{array}$ \\
\hline Fine for Sale & $\begin{array}{c}0.0002 \\
(1.51) \\
\end{array}$ & $\begin{array}{c}0.0002 \\
(1.44) \\
\end{array}$ & $\begin{array}{l}0.0002 \\
(1.07) \\
\end{array}$ & $\begin{array}{l}0.0002 \\
(1.03)\end{array}$ \\
\hline \multicolumn{5}{|c|}{ Panel F: Past Month Use } \\
\hline $\begin{array}{l}\text { Marijuana } \\
\text { Decriminalization }\end{array}$ & $\begin{array}{l}0.011 \\
(0.54) \\
\end{array}$ & $\begin{array}{r}0.006 \\
(0.28) \\
\end{array}$ & $\begin{array}{l}-0.047 \\
(-1.46) \\
\end{array}$ & $\begin{array}{l}-0.046 \\
(-1.42) \\
\end{array}$ \\
\hline $\begin{array}{l}\text { Fine for } \\
\text { Possession }\end{array}$ & $\begin{array}{c}-0.0004 \\
(-2.43) \\
\end{array}$ & $\begin{array}{c}-0.0004 \\
(-2.48) \\
\end{array}$ & $\begin{array}{c}-0.0006 \\
(-2.11) \\
\end{array}$ & $\begin{array}{c}-0.0006 \\
(-2.16) \\
\end{array}$ \\
\hline Fine for Sale & $\begin{array}{c}0.0002 \\
(1.11) \\
\end{array}$ & $\begin{array}{l}0.0002 \\
(1.03)\end{array}$ & $\begin{array}{l}0.0004 \\
(1.62) \\
\end{array}$ & $\begin{array}{l}0.0004 \\
(1.66)\end{array}$ \\
\hline
\end{tabular}

*All models include indicators of gender, race/ethnicity, environment while growing up, work status, religiosity, and year (where appropriate), the continuous measures of age and real weekly income, and an intercept. Model Two adds indicators of family structure, marital status, parents' education, and mother's work status while growing up.

${ }^{* *}$ Asymptotic $t$-ratios are in the parentheses. The critical value for the t-ratios are $2.58(2.33), 1.96(1.64)$, and $1.64(1.28)$ at the one, five, and ten percent significance levels respectively, based on a two-tailed (one-tailed) test. All equations, based on a Chi-square test of $-2 * \log$-likelihood ratio are significant at the one percent significance level.

*** $t$-ratios are in the parentheses. The critical value for the t-ratios are $2.58(2.33), 1.96(1.64)$, and 1.64 (1.28) at the one, five, and ten percent significance levels respectively, based on a two-tailed (one-tailed) test. All equations, based on an $\mathrm{F}$ test are significant at the one percent level. 